Case report

\title{
Unilateral proptosis: extramedullary manifestation of acute myeloid leukaemia
}

\author{
Pallavi Gahlowt, Priyadarshini Cholera, Rajesh Rai, Fehmida Najmuddin, Khushal Avasthi, Keya Lahiri
}

D. Y. Patil Hospital and Medical College, Nerul, Navi Mumbai, India

Received 24 September 2015, Accepted 13 November 2015

(C) 2015, Gahlowt P., Cholera P., Rai R., Najmuddin F., Avasthi K., Lahiri K.

(C) 2015, Russian Open Medical Journal

Abstract: Unilateral proptosis as a sole presentation of acute myeloid leukaemia is not very common. A systematic approach and a peripheral blood smear can help detect and arrest this fatal disease at an early stage. We present a case of acute myeloid leukaemia presenting as unilateral proptosis that was successfully treated with chemotherapy and is in remission.

Keywords: unilateral proptosis, peripheral smear, acute myeloid leukaemia

Cite as Gahlowt P, Cholera P, Rai R, Najmuddin F, Avasthi K, Lahiri K. Unilateral proptosis: extramedullary manifestation of acute myeloid leukaemia. Russian Open Medical Journal 2016; 5: e0105.

Correspondence to Pallavi Gahlowt. Address: D Y Patil Hospital and Medical College, Sector 5, Nerul East, Navi Mumbai Maharashtra, 400706.

E-mail: pallavigahlowt@gmail.com

\section{Introduction}

Leukaemias constitute $15 \%$ of childhood malignancies, of which acute myeloid leukaemia (AML) is one-quarter as common as acute lymphoid leukaemia [1]. AML most commonly affects children and young adults, the median age of presentation being 7 years [2]. In AML, malignant clones of immature myeloid cells (primarily blast cells) proliferate and dominate the bone marrow. Extramedullary leukaemic deposits barely make 3\% of AML cases [3].

\section{Case Report}

A 4-year male presented with gradually progressive unilateral proptosis of the right eye (RE) associated with watering of eyes since 10 days (Figure 1). There was no blurring or double vision, congestion of eyes, squint or orbital pain. There was no history of trauma, bleeding manifestation, bone pain, weight loss or neurological deficit. Left eye was unaffected.

Examination of the RE revealed partial lid closure with proptosis of around $23 \mathrm{~mm}$ on exophthalmometry. Fundus was normal and white reflex was absent. Child was pale and had no lymphadenopathy. Abdominal examination revealed $2.5 \mathrm{~cm}$ firm, palpable liver and spleen measuring $1 \mathrm{~cm}$.

Complete hemogram revealed anemia (hemoglobin $-5.5 \mathrm{~g} / \mathrm{dL}$ ), thrombocytopenia (platelet $-14,000 / \mu \mathrm{L}$ with normal leucocytes $13,800 / \mu \mathrm{L})$. Peripheral blood smear showed anisocytosis, atypical cells and few Auer rods in hand mirror cells. Magnetic resonance imaging (MRI) brain with orbit was suggestive of a well-defined, homogenously enhancing soft tissue lesion measuring $4.0 \times 3.2 \times 2.3 \mathrm{~cm}$ in the extraconal compartments of the right orbit along the right superiorlateral aspect involving the lacrimal gland.

Bone marrow study showed anisocytosis with tear drop cells, $49 \%$ blast cells, $16 \%$ band forms and $9 \%$ eosinophils. Myeloid: erythroid ratio was 3:1 with myeloid series showing increased number of myelocytes and eosinophilic precursors, all of which suggested acute myelo-monocytic leukaemia with bone marrow Eosinophilia. Molecular cytogenetics report showed evidence of AML1/ETO fusion: $\mathrm{t}(8 ; 21)$ in $94 \%$ cells.

The child was initiated on doxorubicin and cytosine arabinoside and after the completion of two cycles, proptosis regressed and bone marrow showed remission (Figure 2). The patient was advised to follow up for consolidation (intensification) cycles. The parents were counseled about the prognosis and probability of a relapse.

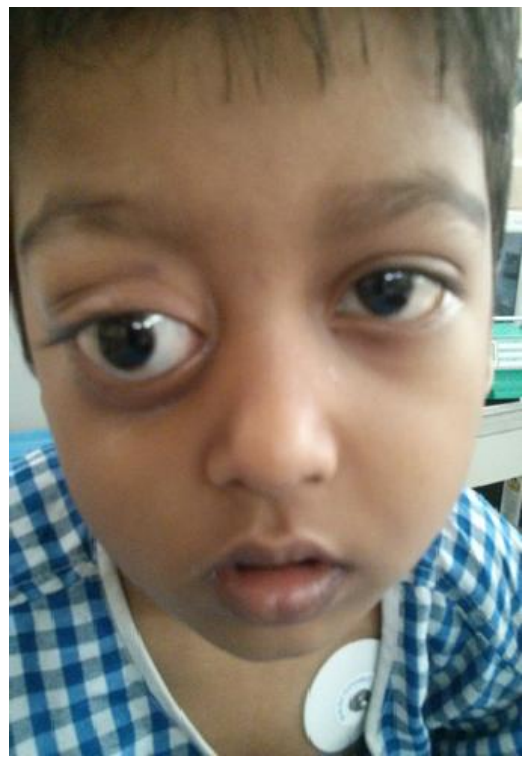

Figure 1. Right eye proptosis before chemotherapy 


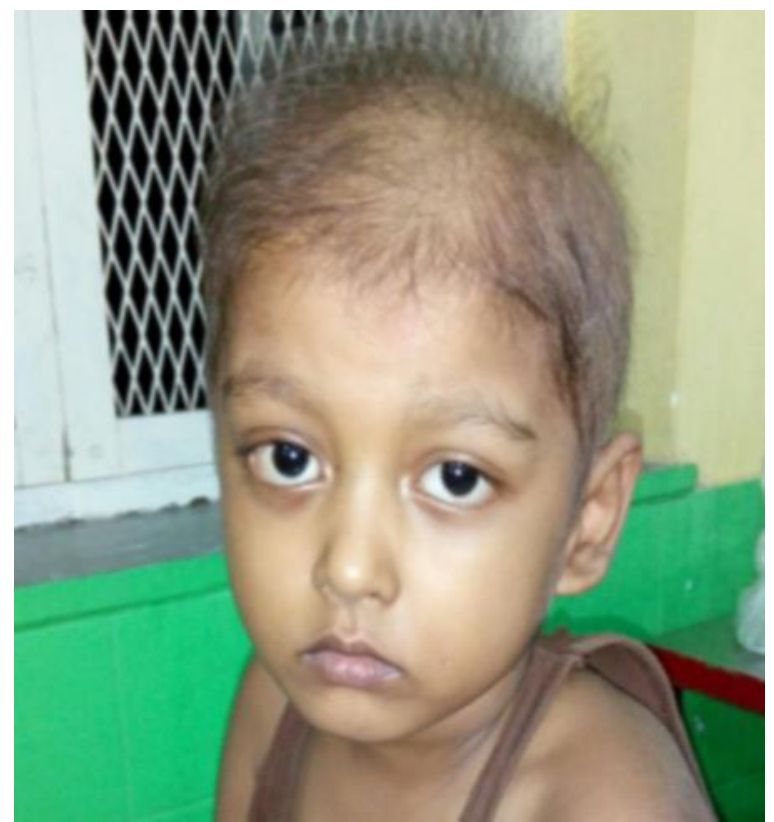

Figure 2. Regression of proptosis after therapy

\section{Discussion}

Proptosis is broadly divided into inflammatory and malignant in origin. Amongst the malignant causes, AML is uncommon and has a good 5- year survival rate of $50-70 \%$ if treated appropriately.

A very crucial aspect in management of leukaemic proptosis is the time lag between its occurrence and the beginning of therapy. Most of the reported cases have decreased visual acuity and restricted extra-ocular movements. Our patient had normal vision and eyeball movements perhaps due to an early detection of leukaemia.

Peripheral blood smear is an invaluable tool in diagnosis of AML. It is cheap, handy and instrumental in the diagnostic modality of AML. Once the diagnosis is confirmed with bone marrow biopsy, chemotherapy remains the mainstay of treatment. The prognosis depends on the course of underlying systemic malignancy. If diagnosed and intervened in time, the outcome is rewarding. Most relapses occur during the initial 2 years of therapy and children are followed up till 5 years after the disease. Despite the advances in chemotherapy, an allogenic bone marrow transplantation from a matched donor still remains the best longterm option that provides remission-free survival for most patients [4].

\section{Conclusion}

Childhood proptosis is an interesting clinical puzzle. A thorough history, clinical examination and few basic laboratory tests often yield positive diagnoses. A peripheral blood smear is mandatory in all cases of proptosis for early detection of malignancy. Early intervention in this potentially fatal disease is often associated with gratifying 5-year survival rates.

\section{Acknowledgements}

Many thanks to the Department of Pathology and Oncology at D Y Patil Hospital and Medical College for their support.
Conflict of interest: none declared.

\section{References}

1. Manola KN. Cytogenetics of pediatric acute myeloid leukaemia. Eur J Haematol 2009; 83: 391-405. (doi: 10.1111/j.1600-0609.2009.01308.x) (PMID: 19563518)

2. Zimmerman LE, Font RL. Ophthalmic manifestations of granulocytic sarcoma (myeloid sarcoma or chloroma). The third Pan American Association of Ophthalmology and American Journal of Ophthalmology Lecture. Am J Ophthalmol 1975; 80: 975-990. (PMID: 1060381)

3. Stockl FA, Dolmetsch AM, Saornil MA, Font RL, Burnier MN Jr. Orbital granulocytic sarcoma. Br J Ophthalmol 1997; 81: 1084-1088. (PMCID: PMC1722070) (PMID: 9497470)

4. Ravindranath $Y$. Recent advances in pediatric acute lymphoblastic and myeloid leukaemia. Curr Opin Oncol 2003; 15: 23-35. (PMID: 12490758)

\section{Authors:}

Pallavi Gahlowt - Paediatric Intensivist, Department of Pediatrics, Dr. D. Y. Patil Hospital and Medical College, Nerul, Navi Mumbai, India.

Priyadarshini Cholera - Medical Director, D. Y. Patil Hospital and Medical College, Nerul, Navi Mumbai, India.

Rajesh Rai - Professor, Paediatrics, D. Y. Patil Hospital and Medical College, Nerul, Navi Mumbai, India.

Fehmida Najmuddin - - Assistant Professor, Paediatrics, D. Y. Patil Hospital and Medical College, Nerul, Navi Mumbai, India.

Khushal Avasthi - Post Graduate, Paediatrics, D. Y. Patil Hospital and Medical College, Nerul, Navi Mumbai, India.

Keya Lahiri - Professor and Head, Paediatrics, D. Y. Patil Hospital and Medical College, Nerul, Navi Mumbai, India. 